\title{
Sources of Sexual Knowledge among Vietnamese High School Students
}

\author{
Kaori Watanabe, Ryoko Saruta, Naomi Kato \\ Department of Midwifery, The Graduate School of Japanese Red Cross Akita College of Nursing, Akita, Japan \\ Email: kaori.w@me.com
}

Received 24 August 2014; revised 24 September 2014; accepted 7 October 2014

Copyright (C) 2014 by authors and Scientific Research Publishing Inc.

This work is licensed under the Creative Commons Attribution International License (CC BY). http://creativecommons.org/licenses/by/4.0/

(c) (i) Open Access

\section{Abstract}

This study determined the sources from which Vietnamese high school students currently acquire sexual knowledge as well as the sources from which they believe they should acquire it. Participants were eleventh-grade students at three public high schools in Hanoi, Vietnam. We conducted a questionnaire-based survey from September to October 2012, with 1672 students participating. Responses were received from all 1672 students, a response rate of $100 \%$. Complete data were received from 1653 respondents (98.9\%), including 896 males (54.2\%) and 757 females (45.8\%). The survey was a self-administrated questionnaire. Although many participants believed that they were knowledgeable about sex, only a small number of them actually possessed accurate sexual knowledge. Few participants in this study, targeted to a specific age (eleventh grade), had used the Internet as a major source for obtaining sexual knowledge, in contrast to results from previous studies which covered a wider age demographic. Future research should include comparative studies between eleventh and twelfth graders as well as between those of the same age who are and who are not enrolled in high school. Additionally, it might be beneficial to consider the relationship between adolescent age and Internet use to study the influence of the Internet on sexual knowledge. Our results suggest that parents and schoolteachers should shoulder more responsibility in providing sexual education, particularly by improving their own knowledge and ability to provide such education, because many participants indicated that sexual knowledge should be acquired from parents and schools.

\section{Keywords}

High School Students, Sexual Knowledge Sources, Internet, Sex Education

\section{Introduction}

In recent years, many Asian countries have achieved remarkable economic development, and the introduction of 
information technology (IT) has been rapidly progressing. One such development is the increased accessibility of information, including sexual information - to which adolescents are indiscriminately exposed [1]. Vietnam is among these progressing Asian countries whose IT is evolving rapidly, and the manner in which adolescents acquire sexual knowledge is simultaneously changing [2]-[5]. Many studies on adolescent sex and sources of sexual knowledge have been conducted in developed countries, including those in Europe and North America [6]-[9]. However, there have been only few such reports made about Vietnam. The representative example was the Survey Assessment of Vietnamese Youth (SAVY), a large-scale national research study conducted in 2003 and 2007 (SAVY 1 and 2) [10] [11]. Later, a detailed report was released that had used SAVY's data to analyze premarital sex and social change. Some additional research pertained to HIV prevention and knowledge as well as the influence of media (particularly IT) on sexual practices among young people [12]-[14]. However, studies investigating the various sources of sexual information in Vietnam were not found.

This study aimed to determine the sources from which Vietnamese high school students currently acquire sexual knowledge and the sources from which they believe they should acquire such knowledge.

\section{Methods}

Participants in this study included 1672 eleventh-grade students from three public high schools in Hanoi-the capital city of the Socialist Republic of Vietnam, populated with 6.844 million people in area of $3323 \mathrm{~km}^{2}$ (Vietnam General Statistics Office-GSO, 2012) [15] [16]. The Center for Population Information and Documentation (CPID), the General Office for Population and Family Planning (GOPFP), and the Ministry of Health of Vietnam all approved of the study. Permission to conduct the survey was also obtained from the authority of each school.

We conducted an anonymous questionnaire-based survey from September to October 2012. The response rate was $100 \%$, as responses were received from all 1672 students. All documents and related materials had first been written in English by us, and then translated into Vietnamese and proofread by the native GOPFP staff. The questionnaire assessed participants' sexual knowledge, awareness of sexual behavior, and perception of peers' sexual intercourse experience.

The high school and GOPFP staff distributed the questionnaires, explaining the details to participants. Then questionnaires were then self-completed by the students, who then sealed their own completed questionnaires in envelopes for privacy protection. Completed surveys were received from 1653 respondents (98.9\%), consisting of 896 males (54.2\%) and 757 females (45.8\%); incomplete surveys were excluded from the analysis.

All analyses were computed using SPSS 17 (Chicago, IL) statistical software.

This study was approved by the Ethical Review Board of the Japanese Red Cross Akita College of Nursing (approval number 24-003). We had the cooperation of the high schools and obtained written informed consent from the participating students.

\section{Results}

Of the 1653 respondents with completed data, 99.9\% were 16 - 18 years old, and most were 16 years old. Most respondents (86.7\%) came from nuclear families. Only 3.9\% of participants were sexually experienced.

Table 1 shows the sexual knowledge of the participants. The percentage of participants who answered correctly which contraceptive method was most effective was $14.8 \%$; $46.9 \%$ knew the proper timing for wearing a condom, and $35.3 \%$ knew what actions should be taken when a condom breaks. Fewer than half the participants knew the correct answers to any of the sexual knowledge questions.

Table 2 shows participants' self-assessment of their own sexual knowledge levels. More than half of both males and females responded affirmatively to the questionnaire item stating, "I have enough sexual knowledge."

Table 3 shows the association between the presence or absence of sex education and sexual knowledge. A significant correlation was found between sex education and the accuracy of one's self-assessment of his or her own sexual knowledge levels. However, sex education was not significantly correlated with the level of one's knowledge.

Table 4 shows the variety of sexual knowledge sources. Major sources for both genders were school (62.1\%) and TV and magazines (73.9\%). Parents were sources for $50.3 \%$ of females. Friends were sources for roughly the same percentages in both genders (36.6\% males, $34.7 \%$ females). Less than $10 \%$ of all respondents selected the Internet as a source. When asked from where sexual knowledge should be acquired, participants selected the 
Table 1. Sexual knowledge of the participants.

\begin{tabular}{ccccccc}
\hline Variable & \multicolumn{2}{c}{ Overall $(\mathrm{n}=1653)$} & \multicolumn{2}{c}{ Male $(\mathrm{n}=896)$} & \multicolumn{2}{c}{ Female $(\mathrm{n}=757)$} \\
\cline { 2 - 7 } & $\mathrm{n}$ & $\%$ & $\mathrm{n}$ & $\%$ & $\mathrm{n}$ & $\%$ \\
\hline Most effective contraceptive method (1 out of 7 choices) & 1597 & & 877 & & 720 & 16.5 \\
Correct answer & 245 & 15.3 & 126 & 14.4 & 119 & 16.5 \\
Wrong answer & 1352 & 84.7 & 751 & 85.6 & 601 & 83.5 \\
Proper timing to wear a condom (1 out of 3 choices) & 1454 & & 851 & & 603 & \\
Correct answer & 775 & 46.9 & 497 & 58.4 & 278 & 46.1 \\
Wrong answer & 679 & 41.1 & 354 & 41.6 & 325 & 53.9 \\
Action to be taken when condom breaks (1 out of 3 choices) & 1415 & & 804 & & 611 & \\
Correct answer & 583 & 41.2 & 321 & 39.9 & 262 & 42.9 \\
Wrong answer & 832 & 58.8 & 483 & 60.1 & 349 & 57.1 \\
\hline
\end{tabular}

Table 2. Self-assessment of sexual knowledge levels.

\begin{tabular}{ccccccc}
\hline & \multicolumn{2}{c}{ Overall $(\mathrm{n}=1653)$} & \multicolumn{2}{c}{ Male $(\mathrm{n}=896)$} & \multicolumn{2}{c}{ Female $(\mathrm{n}=757)$} \\
\cline { 2 - 7 } Variable & $\mathrm{n}$ & $\%$ & $\mathrm{n}$ & $\%$ & $\mathrm{n}$ & $\%$ \\
\hline I have ever received sex education. & 1524 & & 826 & & 698 & \\
Yes & 1121 & 73.6 & 599 & 72.5 & 522 & 74.8 \\
No & 403 & 26.4 & 227 & 27.5 & 176 & 25.2 \\
I have confidence in my sexual knowledge. & 1537 & & 833 & & 704 & \\
Yes & 978 & 63.6 & 573 & 68.8 & 405 & 57.5 \\
No & 559 & 36.4 & 260 & 31.2 & 299 & 42.5 \\
\hline
\end{tabular}

Table 3. Association between the presence or absence of sex education and sexual knowledge.

\begin{tabular}{|c|c|c|c|c|c|c|}
\hline & & Gender & $\begin{array}{l}\text { Most effective } \\
\text { contraceptive method } \\
\text { (correct/wrong) }\end{array}$ & $\begin{array}{l}\text { Proper timing to wear } \\
\text { condom (correct/wrong) }\end{array}$ & $\begin{array}{l}\text { Action to be taken } \\
\text { when condom breaks } \\
\text { (correct/wrong) }\end{array}$ & $\begin{array}{l}\text { I have confidence in } \\
\text { my sexual knowledge. }\end{array}$ \\
\hline \multirow{3}{*}{$\begin{array}{l}\text { Presence or } \\
\text { absence of sex } \\
\text { education }\end{array}$} & Rs & -0.026 & -0.033 & 0.003 & 0.020 & $0.307^{* *}$ \\
\hline & $\mathrm{P}$ & 0.318 & 0.205 & 0.911 & 0.461 & 0.000 \\
\hline & $\mathrm{N}$ & 1524 & 1489 & 1367 & 1333 & 1506 \\
\hline
\end{tabular}

${ }^{* *}$ Correlation is significant at $1 \%$ level (Both sides).

Table 4. Sexual knowledge sources.

\begin{tabular}{|c|c|c|c|c|c|c|}
\hline \multirow{2}{*}{ Variable } & \multicolumn{2}{|c|}{ Overall $(\mathrm{n}=1653)$} & \multicolumn{2}{|c|}{ Male $(\mathrm{n}=896)$} & \multicolumn{2}{|c|}{ Female $(\mathrm{n}=757)$} \\
\hline & $\mathrm{n}$ & $\%$ & $\mathrm{n}$ & $\%$ & $\mathrm{n}$ & $\%$ \\
\hline Where did you acquire sexual knowledge? & 1653 & & 896 & & 757 & \\
\hline School & 1026 & 62.1 & 514 & 57.4 & 512 & 67.6 \\
\hline Parents & 620 & 37.5 & 239 & 26.7 & 381 & 50.3 \\
\hline Siblings & 365 & 22.1 & 170 & 19.0 & 195 & 25.8 \\
\hline Friends & 591 & 35.8 & 328 & 36.6 & 263 & 34.7 \\
\hline TV and magazines & 1222 & 73.9 & 681 & 76.0 & 541 & 71.5 \\
\hline Internet & 121 & 7.3 & 79 & 8.8 & 42 & 5.5 \\
\hline Where should we acquire sexual knowledge from? & 1653 & & 896 & & 757 & \\
\hline School & 854 & 51.7 & 420 & 46.9 & 434 & 57.3 \\
\hline Parents & 725 & 43.9 & 284 & 31.7 & 441 & 58.3 \\
\hline Siblings & 277 & 16.8 & 127 & 14.2 & 150 & 19.8 \\
\hline Friends & 257 & 15.5 & 148 & 16.5 & 109 & 14.4 \\
\hline TV and magazines & 867 & 52.5 & 502 & 56.0 & 365 & 48.2 \\
\hline Internet & 89 & 5.4 & 53 & 5.9 & 36 & 4.8 \\
\hline
\end{tabular}


following sources: school (51.7\%, both genders), TV and magazines (52.5\%, both genders), and parents (58.3\%, only females). Less than $10 \%$ of both genders selected the Internet as an ideal source.

\section{Discussion}

Although many participants in this study believed that they were knowledgeable about sex, only a small percentage of them possessed accurate sexual knowledge. Our findings showed that the majority of participants regarded media such as TV and magazines as sources of information for sexual knowledge; only a small number of participants had acquired knowledge from the Internet—a medium that has been gaining global attention as a source of notable influence among adolescents as well as adults. Ngo et al. conducted a qualitative study on adolescents 15 - 19 years of age in Hanoi, Vietnam, to examine how Internet use shaped their sexual practices and identities. Findings revealed that Internet contributed to the development of young people's identities and intimate practices in two ways: as information sources and as communication tools [14]. However, in our study of eleventh-grade students in Hanoi, very few participants regarded the Internet as their source of sexual information [14]-[18]. This difference in research findings may be because our study limited subjects to students of one specific school year. Subjects in the previous studies represented a wider variability in age and life style; participants included those not attending school as well as students from a range of school years-from third grade to junior high and university level. Results from our study may indicate that uncensored information might not be rampantly spreading among eleventh grade students in Vietnam. Comprehensive analysis of adolescent sexual behavior and attitude requires conducting longitudinal research that takes into account differing ages and backgrounds, as even just a one-year time lag in age or the presence or absence of schooling may affect study outcomes. Areas of future research should include comparative studies between eleventh and twelfth graders as well as between those of the same age who are and who are not enrolled in high school. As many participants indicated that school and parents should be sources of information for sexual knowledge, skillful provision of sexual education should be further developed both at school and at home. Media such as the Internet, TV, and magazines only provide information through one-way communication, limiting the opportunity to recognize and correct individual misunderstandings. Schoolteachers and parents, however, have the opportunity to tailor sexual education according to each individual's need and understanding. Education from the mother, in particular, is to be encouraged, as previous studies have shown the significant role that mothers play in influencing sexual behavior and attitudes among adolescents [19] [20].

\section{Conclusion}

Although many participants believed that they were knowledgeable about sex, only a small number of them possessed accurate sexual knowledge. In contrast to previous studies, this study of eleventh-grade students revealed that very few participants used the Internet as a major source of sexual knowledge. Parents and schoolteachers should be encouraged in taking further responsibility in improving sexual education, by improving their own knowledge and capability to provide such education, as many participants indicated that sexual knowledge ought to be acquired from these sources. Future research shall include comparative studies between eleventh and twelfth graders as well as between those of the same age who are and who are not enrolled in high schools.

\section{Acknowledgements}

We are grateful for the collaboration of staff members from the Ministry of Health; the Center for Population Information and Documentation (CPID); the General Office for Population and Family Planning (GOPFP) of the Socialist Republic of Vietnam; and participating high school staff members, students, and their parents and guardians.

\section{References}

[1] Banaji, S. (2006) Loving with Irony: Young Bombay Viewers Discuss Clothing, Sex and Their Encounter with Media. Sex Education, 6, 377-391. http://dx.doi.org/10.1080/14681810600982044

[2] Mensch, B., Clark, W. and Dang, N. (2002) Premarital Sex in Vietnam: Is the Current Concern with Adolescent Reproductive Health Warranted? Population Council No. 163. http://www.popcouncil.org/pdfs/wp/163.pdf

[3] Gammeltoft, T. (2002) Seeking Trust and Transcendence: Sexual Risk-Taking among Vietnamese Youth. Social 
Science \& Medicine, 55, 483-496. http://dx.doi.org/10.1016/S0277-9536(01)00182-4

[4] Nguyen, B.T. and Thomas, M. (2004) Young Women and Emergent Postsocialist Sensibilities in Contemporary Vietnam. Asian Study Review, 28, 133-149. http://dx.doi.org/10.1080/1035782042000226684

[5] Ghuman, S., Loi, V., Huy, V. and Knodel, J. (2006) Continuity and Change in Premarital Sex in Vietnam. International Family Planning Perspectives, 32, 166-174. http://dx.doi.org/10.1363/3216606

[6] Bleakley, A., Hennessy, M., Fishbein, M. and Jordan, A. (2009) How Sources of Sexual Information Relate to Adolescents' Belief about Sex. American Journal of Health Behavior, 33, 37-48. http://dx.doi.org/10.5993/AJHB.33.1.4

[7] Guan, S.-S.A. and Subrahmmanyan, K. (2009) Youth Internet Use: Risks and Opportunities. Current Opinion in Psychiatry, 22, 351-356. http://dx.doi.org/10.1097/YCO.0b013e32832bd7e0

[8] Strasburger, V.C. (2012) Adolescents, Sex, and the Media. Adolescent Medicine: State of the Art Reviews, 23, 15-33, ix. Review.

[9] Liliana Escobar-Chaves, S., Tortolero, S., Markham, C., Low, B., Eitel, P. and Thickstun, P. (2005) Impact of the Media on Adolescent Sexual Attitudes and Behaviors. Pediatrics, 116, 303-326.

[10] Ministry of Health, General Statistic Office, World Health Organization and the United Nations Children Fund (2005) Survey Assessment of Vietnamese Youth Round 1 (SAVY 1). Hanoi.

[11] Ministry of Health, General Statistic Office, World Health Organization and the United Nations Children Fund (2010) Survey Assessment of Vietnamese Youth Round 2 (SAVY 2). Hanoi.

[12] van Wijingaarden, J. (2006) UNICEF Consultant Exploring Factors and Processes Leading to HIV Risk among the Most Vulnerable Children and Adolescent in Vietnam.

[13] Taechaboonsermsak, P., Tuan, L. and Apinuntavech, S. (2008) Factors Associated with HIV/AIDS Preventive Behavior among High School Students in Dongda District, Hanoi, Vietnam. Journal of Public Health, 38, 174-185.

[14] Ngo, A., Ross, M. and Ratliff, E. (2008) Internet Influence on Sexual Practice among Young People in Hanoi, Vietnam. Culture, Health \& Sexuality, 10, S201-S213. http://dx.doi.org/10.1080/13691050701749873

[15] United Nations Department of Economic and Social Affairs Population Division. http://www.un.org/en/development/desa/population/

[16] General Statistics Office of Vietnam Statistical Handbook 2012. http://www.gso.gov.vn/default_en.aspx?tabid=515\&idmid=5\&ItemID=13700

[17] Brown, J.D. and Keller, S.N. (2000) Can the Mass Media Be Healthy Sex Educators? Family Planning Perspectives, 32, 255-256. http://dx.doi.org/10.2307/2648180

[18] Hoff, T., Greene, L. and Davis, J. (2003) National Survey of Adolescents and Young Adults: Sexual Health Knowledge, Attitudes, and Experiences. Kaiser Family Foundation, Menlo Park.

[19] Sieving, R.E., McNeely, C.S. and Blum, R.W. (2000) Maternal Expectations, Mother-Child Connectedness, and Adolescent Sexual Debut. Archives of Pediatrics \& Adolescent Medicine, 154, 809-816. http://dx.doi.org/10.1001/archpedi.154.8.809

[20] Trinh, T., Steckler, A., Ngo, A. and Ratliff, E. (2009) Parent Communication about Sexual Issues with Adolescents in Vietnam: Content, Contexts, and Barriers. Sex Education: Sexuality, Society and Learning, 9, 371-380. 
Scientific Research Publishing (SCIRP) is one of the largest Open Access journal publishers. It is currently publishing more than 200 open access, online, peer-reviewed journals covering a wide range of academic disciplines. SCIRP serves the worldwide academic communities and contributes to the progress and application of science with its publication.

Other selected journals from SCIRP are listed as below. Submit your manuscript to us via either submit@scirp.org or Online Submission Portal.
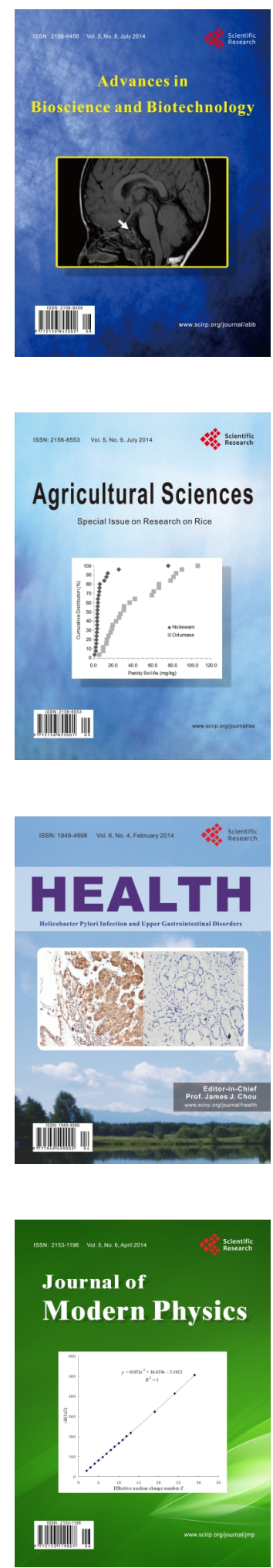
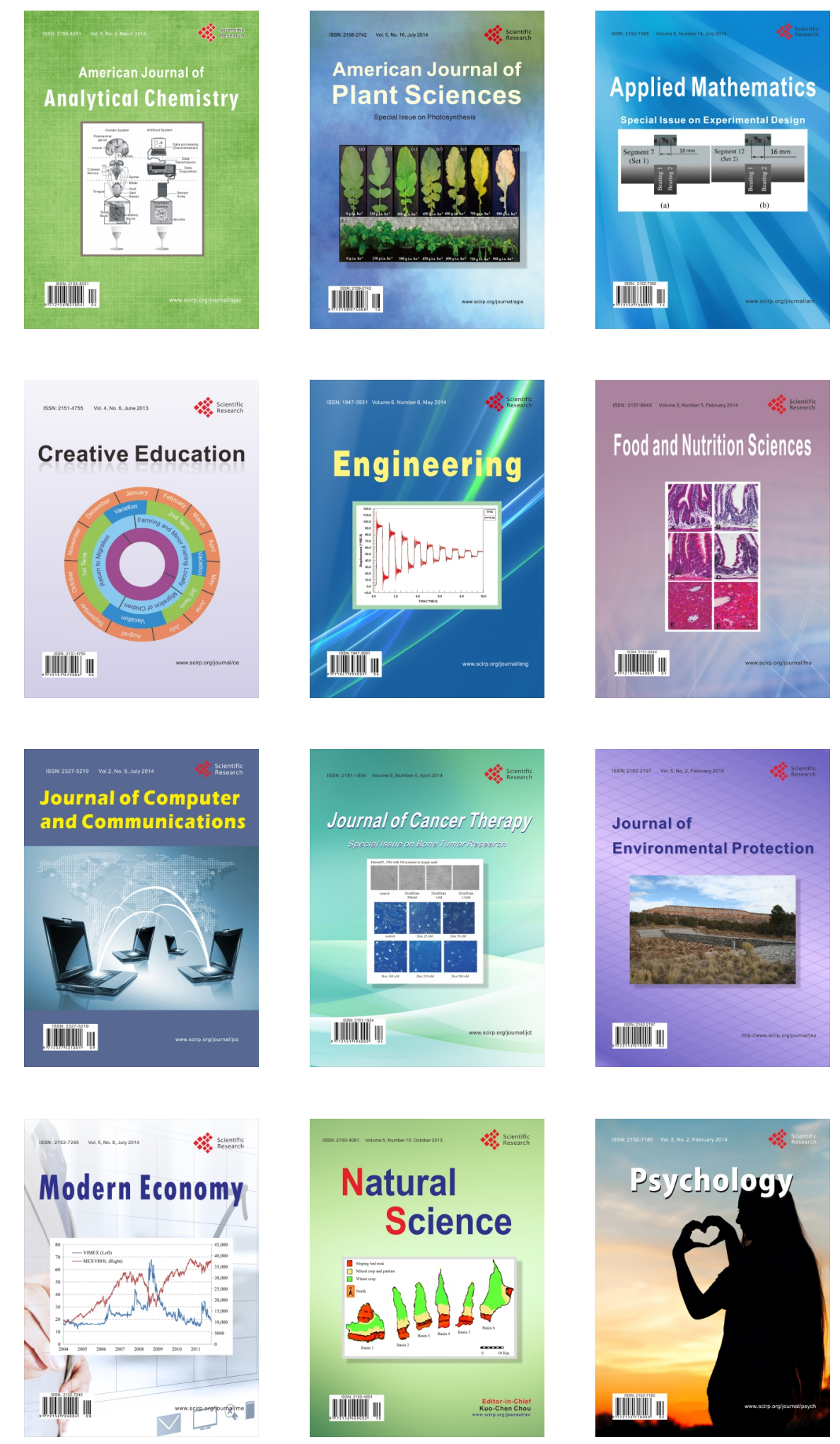